\title{
Streptococcus pneumoniae as an Uncommon Cause of Superinfected Pancreatic Pseudocysts
}

\author{
C. Gubler, A. Zinkernagel, N. Ossola, P. Bauerfeind
}

\begin{abstract}
We report a patient with pancreatic pseudocysts that were superinfected with Streptococcus pneumoniae. The literature on the prevalence of superinfection of pancreatic tissue by S. pneumoniae, as well as on its prophylaxis and treatment, is reviewed. In addition, a possible pathophysiologic pathway is discussed.
\end{abstract}

Infection 2003; 31: 251-253

DOI 10.1007/s15010-003-4019-z

\section{Introduction}

Superinfection of necrotic pancreatic tissue, peripancreatic fluid and pseudocysts is well known to cause serious complications in both acute and chronic pancreatitis. It results in significant morbidity and mortality. Predominantly, gramnegative aerobic bacteria, such as Echerischia coli, Pseudomonas ssp., Proteus and Klebsiella ssp., are found as causative organisms. Uncommonly, gram-positive bacteria, such as Staphylococcus aureus, Enterococcus faecalis and fungi, can be isolated [1]. Since 40 to $50 \%$ of the patients suffering from necrotizing pancreatitis develop bacterial superinfection [2], prophylactic administration of antibiotics is recommended [3]. If superinfection of pancreatic pseudocysts is suspected, microbiologic sampling should be attempted $[4,5]$ to establish an appropriate antibiotic therapy.

\section{Case Report}

A 45-year-old Caucasian man, with a history of alcohol abuse, presented to our tertiary hospital because of upper abdominal pain which had worsened over a period of 5 weeks. Three weeks prior to admission, he observed jaundice of the eyes, darkening of the urine and pale watery stools. A weight loss of $8 \mathrm{~kg}$ over the last 2 months was reported. His medical history revealed no signs of gastrointestinal bleeding, hepatic cirrhosis, diabetes mellitus and no history of pancreatitis. Physical examination was unremarkable, except for pain in the upper abdominal quadrants on deep palpation, without signs of peritonitis.

Laboratory test showed an elevated pancreatic amylase (206 U/1), a slight leukocytosis $\left(9.8 \times 10^{3} \mu \mathrm{l}\right)$ and a C-reactive protein (CRP) of $9 \mathrm{mg} / \mathrm{l}$ (reference value $<5 \mathrm{mg} / \mathrm{l}$ ). An acute viral hepatitis caused by hepatitis viruses $\mathrm{A}, \mathrm{B}$ or $\mathrm{C}$ was excluded.

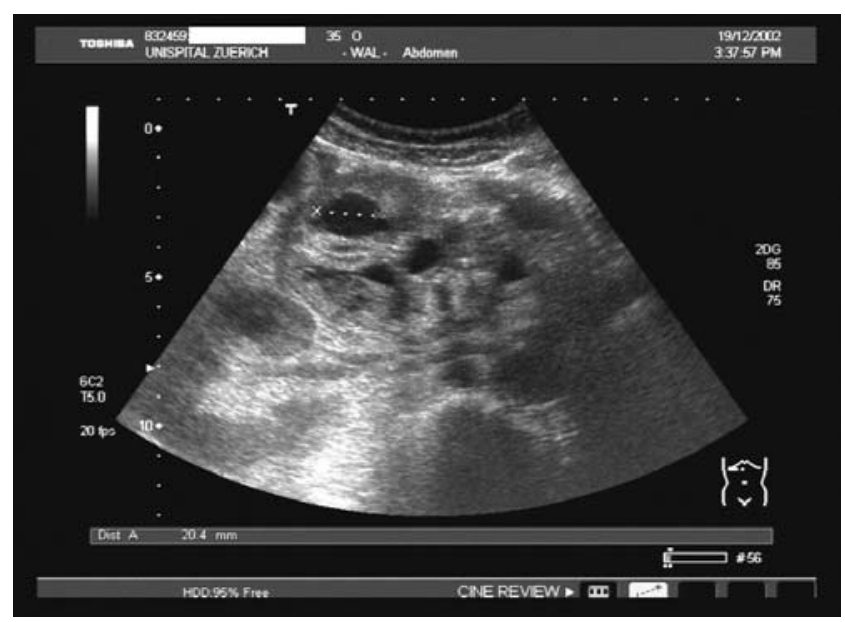

Figure 1. Pancreatic pseudocysts demonstrated by ultrasound.

Both the computed tomography (CT) and ultrasound of the abdomen showed the head of the pancreas to be enlarged, with multiple calcifications. The whole pancreatic duct was irregularly dilated. The peripancreatic fat was homogeneously infiltrated as far as the abdominal wall. Three small pseudocysts were present, the largest of which measured $3.5 \times 2 \mathrm{~cm}$ (Figure 1). An acute episode of a chronic alcoholic pancreatitis with pseudocysts was diagnosed.The patient's situation improved within the next 4 days while fasting. Pancreatic amylase returned to normal values. After 1 week, having resumed oral alimentation, the abdominal pain increased, as did the CRP and the leukocytes. We suspected a secondary infection of the pseudocysts and therefore performed an ultrasound-guided puncture of the most accessible cyst; pus was

\footnotetext{
C. Gubler, P. Bauerfeind (corresponding author)

Dept. of Gastroenterology and Hepatology, University Hospital of Zurich, $\mathrm{CH}-8091$ Zurich; Switzerland; Phone: (+41/1) 255-1111, Fax: -4503,

e-mail: peter.bauerfeind@usz.ch

A. Zinkernagel

Dept. of Infectious Disease, University Hospital of Zurich, Switzerland N. Ossola

Dept. of Internal Medicine, University Hospital of Zurich, Switzerland

C. Gubler and A. Zinkernagel contributed equally to this work
}

Received: February 12, 2003 - Revision accepted: May 5, 2003 
aspirated and gram-positive diplococci were visualized. Culture revealed penicillin-sensitive Streptococcus pneumoniae.

Intravenous antibiotic therapy with amoxicillin and metronidazole was initiated, the patient improved and nutrition could be established without pain. Metronidazole was stopped after anaerobic organisms were excluded and amoxicillin was continued for a total of 3 weeks. Therapy was not switched to penicillin G considering the ease of administration and the possibility to treat the patient in an ambulatory setting.

\section{Discussion}

In Western countries, alcohol abuse is the predominant etiology of chronic pancreatitis. In about $20 \%$ of patients with calcifications of the pancreatic tissue, there is no history of abdominal pain or of acute pancreatitis [6]. The discrimination between chronic and acute pancreatitis is crucial because of the different mortality rates. In acute pancreatitis, mortality rises from $1 \%$ to $15 \%$ if necrosis develops and to $35 \%$ if a superinfection occurs [7]. The latter will develop after the first 10 to 14 days in about $60 \%$ of all patients [8]. Early antibiotic prophylaxis should be part of standard treatment in severe pancreatitis and reduces the infection rate to about 30\% [9]. In 1998, a meta-analysis of eight prospective trials showed a significant reduction of mortality by routine administration of broad-spectrum antibiotics, such as imipenem, in cases with necrosis $[3,10]$. As a consequence of this policy, there has been a shift from gram-negative to gram-positive microorganisms and fungi $[10,11]$. Standard treatment for an infected necrosis is surgery or drainage [12].

Pancreatic pseudocysts represent a different entity compared to infected necroses with or without abscess [13]. The policy concerning when and how to drain noninfected pseudocysts is discussed elsewhere [14]. If an infection within the pseudocyst is assumed, microbiological analysis by puncture of the cyst should be attempted, either percutaneously or by ultrasound-guided endoscopy. Culture should guide antimicrobial therapy, since the microbiologic spectrum can be broad.

In this case, the Gram stain revealed gram-positive cocci that were subsequently identified as $S$. pneumoniae. In view of the literature on case reports and laboratory analyses, this finding was not altogether surprising.

Although rare, involvement of $S$. pneumoniae in pancreatic disease has been described previously [15] and was always associated with alcoholism. To date, S. pneumoniae was identified as the causative microorganism of pancreatic disease in one case report [16] and in a group of nine patients from Hungary [17]. The route of infection of the pancreatic lesions remains unclear. An explanation may be found by studying the high prevalence of S. pneumoniae bacteremia in alcoholics [18, 19].

A well-defined mechanism causing pneumonia and bloodstream infections is aspiration during periods of high serum alcohol levels. In addition, malnutrition and poor hygiene, especially neglected dental status, contribute to a higher incidence of bloodstream infections. Once the bac- teria have entered the bloodstream, they should be controlled by the immune system. However, chemokine production is impaired in patients with high alcohol levels. This results in insufficient recruitment of macrophages and, therefore, a much higher probability of bacteremia $[18,19]$. Necrotic tissue and pseudocysts are found in noninfectious pancreatitis. They offer ideal cultural growth conditions for bacteria arriving via the bloodstream. This could explain why superinfection of pancreatic tissue with S. pneumoniae is most frequently found in alcoholics.

Considering the literature and the probable pathophysiologic mechanisms, prophylaxis should be part of the standard treatment for severe pancreatitis to reduce the infection rate. If an infection within the pseudocyst is assumed, microbiological analysis by puncture of the cyst and early antibiotic treatment should be attempted if no prophylaxis had been given.

\section{References}

1. Garg PK, Khanna S, Bohidar P, Kapil A, Tandon RK: Incidence, spectrum and antibiotic sensitivity pattern of bacterial infections among patients with acute pancreatitis. J Gastroenterol Hepatol 2001; 16: 1055-1059.

2. Beger HG, Bittner R, Block S, Buchler M: Bacterial contamination of pancreatic necrosis. A prospective clinical study. Gastroenterology 1986; 91: 433-438.

3. Golub R, Siddiqi F, Pohl D: Role of antibiotics in acute pancreatitis; a meta-analysis. J Gastrointest Surg 1998; 2; 496-503.

4. Yousaf M, McCallion K, Diamond T: Management of severe acute pancreatitis. Br J Surg 2003; 90: 407-420.

5. Rau B, Pralle U, Mayer M, Beger HG: Role of ultrasonographically guided fine-neddle aspiration cytology in the diagnosis of infected pancreatic necrosis. Br J Surg 1998; 85: 179-184.

6. Layer P, Yamamoto H, Kalthoff L, Clain JE, Bakken LJ, DiMagno EP: The different courses of early and late onset idiopathic and alcoholic chronic pancreatitis. Gastroenterology 1994; 107: 1481-1487.

7. Vesentini S, Bassi C, Talamini G, Cavallini G, Campedelli A, Pederzoli P: Prospective comparison of C-reactive protein level, Ranson score and contrast-enhanced computed tomography in the prediction of septic complications of acute pancreatitis. $\mathrm{Br} \mathrm{J}$ Surg 1993; 80: 755-757.

8. Gerzof SG, Banks PA, Robbins AH, Johnson WC, Spechler SJ, Wetzner SM, Snider JM, Langevin RE, Jay ME: Early diagnosis of pancreatic infection by computed tomography-guided aspiration. Gastroenterology 1987; 93; 1315-1320.

9. Gloor B, Müller C, Worni M, Stahel PF, Redaelli C, Uhl W, Buchler MW: Pancreatic infection in severe pancreatitis. Arch Surg 2001; 136; 592-596.

10. Bassi C, Falconi M, Talamini G, Uomo G, Papaccio G, Dervenis C, Salvia R, Minelli EB, Pederzoli P: Controlled clinical trial of pefloxacin versus imipenem in severe acute pancreatitis. Gastroenterology 1998; 115: 1513-1517.

11. Büchler MW, Gloor B, Müller C, Friess H, Seiler CA, UhI W: Acute necrotizing pancreatitis: treatment strategy according to the status of infection. Ann Surg 2000; 232: 619-626.

12. Schmid SW, UhI W, Friess $\mathrm{H}$ : Review: the role of infection in acute pancreatitis. Gut 1999; 45: 311-316. 
13. Fedorak IJ, Ko TC, Djuricin G, McMahon M, Thompson K, Prinz RA: Secondary pancreatic infections: are they distinct clinical entities? Surgery 1992; 112: 824-830.

14. Seifert H, Binmoeller KF, Sohendra N: Pancreatic pseudocysts: how and when should they be drained? Bildgebung 1995; 62 (suppl 1): 12-18.

15. Taylor S, Sander C: Unusual manifestations of invasive pneumococcal infection. Am J Med 1999; 107; 12-27.

16. Denis F, Mounier M, Descottes B, Cubertafond P, Catanzano G: Abdominal infections caused by Streptococcus pneumoniae. Eur J Clin Microbiol 1984; 3: 443 .
17. Thege M, Pulay I, Balla E, Tihanyi T: Streptococcus pneumoniae as an etiologic agent in infectious complications of pancreatic disease. Microb Drug Resist 2002; 8: 73-76.

18. Stanford TJ, Danforth J: Ethanol feeding inhibits proinflammatory cytokine expression from murine alveolar macrophages ex vivo. Alcohol Clin Exp Res 1997; 21: 1212-1217.

19. Boé DM, Nelson S, Zhang P, Bagby GJ: Acute ethanol intoxication suppresses lung chemokine production following infection with S. pneumoniae. J Inf Dis 2001; 184: 1134-1142.

\section{Editor's Note}

The case report of $C$. Gubler et al. above will be the last contribution to the series Clinical Quiz for the time being.

The correct answer to Quiz Case Infection 3/2003 is Streptococcus pneumoniae.

The editor would like to thank all those who have contributed to this section. 